\title{
NÓS DO MUNDO: UM DIÁLOGO EDUCATIVO SOBRE A SUSTENTABILIDADE
}

\author{
Alessandro Franco Machado Batista \\ Laís Lacerda Viana \\ Vanessa Fernandes Guimarães
}

\section{Resumo}

O presente artigo consiste no relato e análise da experiência de educação não formal de uma exposição interativa sobre o tema da sustentabilidade, desenvolvida no âmbito do Museu da Vida, da Casa de Oswaldo Cruz, unidade pertencente à Fundação Instituto Oswaldo Cruz (Fiocruz). A exposição denominada "Nós do Mundo" foi concebida, elaborada e visitada no contexto da conferência internacional "RIO + 20" e promoveu amplo debate sobre a questão ambiental com o público visitante do Museu da Vida, no ano de 2012. O trabalho se delimita no campo da educação não formal em sua relação com o movimento ambientalista e seus debates. Aborda por meio do trabalho da exposição e da reflexão sobre as práticas educativas utilizadas, as variadas possibilidades de se discutir com a sociedade os temas da degradação ambiental de nosso planeta inseparáveis das questões das iniquidades sociais.

\section{Abstrat}

This article is a case study reporting and analyzing the informal education approach of an interactive exhibition on the theme of sustainability and developed by the Museum of Life of House of Oswaldo Cruz of Oswaldo Cruz Foundation Fiocruz. The exhibition "Nós do Mundo" was conceived and presented in 2012 within the context of the United Nations Conference on Sustainable Development - 
$\mathrm{RIO}+20$ and promoted a broad debate on relevant environmental issues with the museum's public. The present study discusses the possible contributions of informal learning initiatives to the environmentalism and to increase the public awareness on this theme. It presents through the analysis of the exhibition and the educational activities related to it some diverse approaches to foster the social debate on the environmental degradation of our planet and other pressing related issues as social inequalities.

\section{Introdução}

O sistema social capitalista atualmente hegemônico em nosso planeta possui seu modelo econômico baseado, no lucro promovido fundamentalmente pelo consumo infinito e pela expropriação do trabalho executado pelos produtores da riqueza em nossa sociedade (Benjamin, 1987).

O avanço de uma lógica social de acumulação infinita, ancorada no desenvolvimento cientifico e tecnológico cada vez mais predador da natureza, dos homens e de suas consciências conduziu à nossa sociedade a uma encruzilhada dificil de ser superada.

O capitalismo transformou-se não apenas na tecnologicamente mais produtiva das sociedades históricas como também na mais destrutiva de todas. Pois um universo de lixo é lançado fora a todo momento por essa enorme máquina produtora de mercadorias onde despeja seus dejetos na natureza. Simultaneamente extrai de forma indiscriminada dessa mesma natureza, absolutamente qualquer coisa que possa tornar-se mercadoria útil e vendável no mercado (Meszáros, 1989).

A história da modernização burguesa, do seu nascimento até a sua conversão em aldeia global, pode ser percebida como uma imensa acumulação de catástrofes ecológicas, que culmina com a interferência da dinâmica climática mundial (lanni, 1995). 
Diante desta crise, da grande e crescente pressão popular, objetivando minimizar danos desde a década de 1970 a ONU (Organização das Nações Unidas) vem realizando conferências internacionais de meio ambiente itinerantes, cuja uma das mais famosas sem dúvida foi a ocorrida no Rio de Janeiro em 1992, conhecida como ECO - 92. Após vinte anos nova conferência foi realizada no Rio de Janeiro com uma proposta incial de formular uma espécie de "avaliação" de avanços e retrocessos referentes ao que tinha sido proposto e firmado como metas internacionais pelas nações desde então, este evento ficou conhecido como Rio + 20, que ocorreu em 2012, em uma evidente alusão a conferência anterior.

No bojo desse contexto histórico e da relevância que se alinhavava na realização da Rio + 20, o Museu da Vida/COC/FIOCRUZ, colaborou com esta discussão junto a sociedade brasileira elaborando uma exposição que abordava 0 tema referente a degradação ambiental e sua relação com o modo de produção hegemônico, nomeada "Nós do Mundo".

O presente artigo objetiva apresentar a exposição: seu conteúdo base, sua organização e sua diretriz educativa como experiência importante para promover o diálogo com a sociedade sobre as questões aqui apresentadas.

O nosso texto está organizado da seguinte forma no item velhos hábitos, novas tecnologias temos contato com o conteúdo base da exposição de onde a curadoria pode construir em diálogo com os demais profissionais do museu o conteúdo expositivo. Na sequência abordamos a organização dos módulos da exposição propriamente dita, e depois apresentamos a proposta educativa e sua dinâmica diálogica com a visitação em curso. Por fim uma breve consideração final sobre as diversas possibilidades que este trabalho aponta.

\section{Velhos hábitos, novas tecnologias}

O atual modelo econômico oriundo da revolução industrial, embora predador dos recursos naturais, acelerou o crescimento econômico e gerou elevação no nível de bem estar das populações. Ao longo dos séculos foi se 
refinando e se beneficiando dos avanços da ciência e tecnologia, mantendo, entretanto seu paradigma de consumo infinito de recursos finitos.

O modelo econômico vigente capitalista é sustentado pelo lucro e, utiliza-se dos meios de comunicação para propagar a idéia do que precisamos para sobreviver. Baseia-se na economia de mercado e na cultura do consumo.

No início do século XX uma orientação consumista tornou-se cada vez mais incorporada a muitas das instituições sociais dominantes nas diversas culturas dos negócios aos governos, da mídia à educação. A partir da última metade do século, inovações como a televisão, técnicas sofisticadas de marketing, corporações transnacionais, franchises e a internet ajudaram a espalhar 0 consumismo através do planeta. Medidas econômicas como a liberalização do crédito, através dos crediários e a ampliação do uso e acesso ao cartão de crédito contribuíram para fomentar esta febre de consumo. Além disto, os produtos passaram a ser projetados para terem baixa durabilidade ou saírem de moda rápido - estratégias denominadas de obsolescência física e psicológica respectivamente. Os trabalhadores são estimulados a trabalharem mais horas para ganharem mais e gastarem mais com itens de consumo (Mészaros, 1989).

Hábitos de consumo, também, têm raízes sociais. O consumo é, em parte, um ato social por meio do qual as pessoas expressam suas identidades pessoais e grupais e também o seu status social. Motivadores sociais podem ser impulsionadores insaciáveis de consumo, contrastando com o desejo por alimento, água ou outros bens, que está circunscrito aos limites da capacidade humana. Tais desejos podem ser ilimitados e, portanto, ter o potencial de manter 0 consumo em constante crescimento.

O consumo cresceu dramaticamente durante as últimas 5 décadas, os 4,9 trilhões de dólares gastos em 1960 aumentaram para \$23,9 trilhões (atualizados para valores de 2008) em 1996, e estes cresceram aproximadamente $28 \%$ até 2008 (UNESCO).

Parte deste crescimento deve-se ao crescimento da população, mas 0 aumento no número de pessoas foi de 2.2 vezes entre 1960 e 2006. 
Consequentemente os gastos com consumo por pessoa quase triplicaram neste período.

À medida que o consumo foi crescendo, mais combustíveis fósseis, minerais e metais foram extraídos da terra, mais árvores foram cortadas e mais terras foram usadas para agricultura (frequentemente para alimentar os rebanhos, na medida em que as pessoas com maior renda passaram a comer mais carne). Entre 1950 e 2005, por exemplo, a produção de metais cresceu 6 vezes, o consumo de petróleo aumentou 8 vezes e o consumo de gás natural 14 vezes. Atualmente, no total 60 bilhões de toneladas de recursos são extraídos anualmente - cerca de $50 \%$ a mais do que apenas 30 anos atrás. Hoje, o europeu médio usa $43 \mathrm{~kg}$ de recursos diariamente e o estadunidense médio usa $88 \mathrm{~kg}$.

A exploração destes recursos para manter os sempre crescentes níveis de consumo tem imposto uma pressão crescente sobre os sistemas da Terra e seus ecossistemas. As alterações em um destes serviços ecossistêmicos em particular, a regulação climática é especialmente preocupante. Após permanecer estável durante o último milênio em cerca de 280 ppm, a concentração atmosférica de dióxido de carbono (CO2), um dos principais gases de efeito estufa (GEE), está agora em 385 ppm, devido ao crescimento da população e o seu sempre crescente consumo de combustíveis fósseis, de carne e a conversão de cada vez mais áreas naturais em áreas urbanas e agrícolas. O Painel Intergovernamental sobre Mudanças Climáticas tem alertado sobre a necessidade iminente de reduzir a emissão de gases de efeito estufa para mitigar os efeitos desastrosos do aquecimento global.

Segundo a UNESCO, um estudo realizado em setembro de 2009 utilizando - Modelo Integrado de Sistemas Globais do Instituto de Tecnologia de Massachusetts descobriu que se mantivermos o atual modelo econômico haverá um aumento de 4,5 graus Celsius na temperatura global em 2100 e que mesmo que todos os países atinjam suas metas mais ambiciosas de redução na emissão de GEE, ainda assim as temperaturas globais aumentarão em média 3,5 graus Celsius. Ou seja, políticas apenas não serão suficientes, será necessária uma 
mudança nas bases das sociedades humanas. Estes níveis projetados de alteração nas temperaturas provavelmente resultarão numa elevação de 2 ou mais metros no nível dos oceanos devido ao degelo parcial da regiões polares o que ocasionará uma inundação massiva das áreas costeiras e potencialmente a submersão de nações insulares. A sexta parte da população mundial que depende de glaciares ou de rios oriundos do degelo sazonal se defrontará com uma extrema escassez de água. Os habitantes das regiões costeiras inundadas também enfrentarão problemas devido à salinização dos aqüíferos devido à contaminação pela água do mar.

Estudos sobre mudanças climáticas mostram que vastas porções da Floresta Amazônica tornar-se-ão savanas, os recifes de coral e boa parte da vida marinha, incluindo os principais pesqueiros, morrerão devido à elevação da temperatura e acidificação dos oceanos. Tudo isto se traduzirá em grandes perturbações políticas e sociais com um número de refugiados ambientais que deve alcançar cerca de 1 bilhão de pessoas por volta de 2050 .

A mudança climática é apenas um dos muitos sintomas dos níveis excessivos de consumo. A poluição do ar, a perda média de 7 milhões de hectares de florestas por ano, a erosão do solo, a produção anual de mais de 100 milhões de toneladas de lixo tóxico, práticas trabalhistas abusivas decorrentes da necessidade de produzir bens de consumo mais baratos e em maior quantidade, ampliação das desigualdades e da miséria, maior incidência de doenças transmitidas por vetores, surgimento de doenças emergentes, etc (Marengo; Valverde; 2007).

A lista de problemas é quase interminável. Todos estes problemas, em geral, são tratados isoladamente apesar de a maioria ter suas raízes nos atuais padrões de consumo. Entretanto há fortes evidências de que maiores níveis de consumo não aumentam significativamente a qualidade de vida além de um determinado ponto, podendo mesmo reduzi-la (Lobo; 2010).

Este modelo, além de criar profundas desigualdades uma vez que poucos se beneficiam dele, é perverso na medida em que os excluídos, geralmente 
deslocados para as periferias e dependentes dos recursos naturais para garantirem a sua sobrevivência, são os que mais sofrem com as conseqüências da destruição ambiental.

Este modelo tornou-se insustentável justamente em função deste consumo intensivo e exagerado dos recursos naturais. Ele é auto-limitado. A exaustão da capacidade dos ecossistemas suportarem a pressão da atividade econômica restringirá o próprio crescimento econômico, além de causar graves prejuízos ao meio ambiente e ao clima, ameaçando a sobrevivência da espécie humana.

\section{A exposição Nós do Mundo}

A exposição Nós do Mundo é composta por três módulos nomeados "Visões do Planeta", "Cenários" e "Interativos"1.

No acolhimento inicial da visita na porta de entrada da exposição, em meio a um pequeno jardim de plantas naturais, o visitante era recepcionado e informado do tema da exposição, sua organização, regras de convivência e relação com a conferência da RIO + 20 e com o evento cúpula dos povos organizado pelos movimentos sociais e organizações diversas alternativo e paralelo a conferência.

No módulo "Visões do Planeta" os visitantes são convidados a contemplar imagens que abordam a biodiversidade do planeta e deparar-se com estatísticas sobre a degradação da vida e do meio ambiente. A fim de estimular a reflexão sobre o impacto no meio ambiente, foram desenvolvidas "perguntas chaves", para que os visitantes relacionassem a biodiversidade do planeta com o habitat de diferentes espécies, deixando evidente que a luta pelo planeta é a luta pela sobrevivência de nossa espécie.

A mediação pode ser dialogicamente explorada com público de todas as idades, onde sua dinâmica foi dividida em dois momentos distintos. No primeiro momento, através das imagens, o público foi levado a observar a biodiversidade e

\footnotetext{
${ }^{1}$ Link para visualização dos módulos expositivos

http://www.flickr.com/photos/museudavida/sets/72157629957352166/
} 
o habitat de diversas espécies existentes no planeta, entendendo-se também como parte de meio ambiente e responsável direto pela preservação deste. No segundo momento o público foi direcionado as placas acima das imagens e induzido a refletir sobre os problemas que "pairam sobre nossas cabeças", entendendo-se como sujeito histórico responsável pelas mudanças futuras (Freire, 1996).

Para melhor alcançarmos nossos objetivos, houve necessidade de trabalhar individualmente o conteúdo de quase todas as placas com o público abaixo de 10 anos durante as visitas guiadas a exposição. Entendemos que alguns assuntos abordados ainda não faziam parte dos conteúdos trabalhados em sala de aula até o momento, e que em certe medida limitava a exposição oral, contudo, propiciava uma mediação que explorava as imagens com os visitantes (Lobo; 2010) .

O módulo "Cenários" apresentou aos visitantes dois murais distintos, contendo no primeiro cenários negativos; lixo; poluição; consumo excessivo; desigualdade social; fome; e no segundo cenário possíveis soluções para tais problemas, como alternativas de "energia limpa"; trabalho cooperativo; novas tecnologias; entre outros.

Imagem 1 


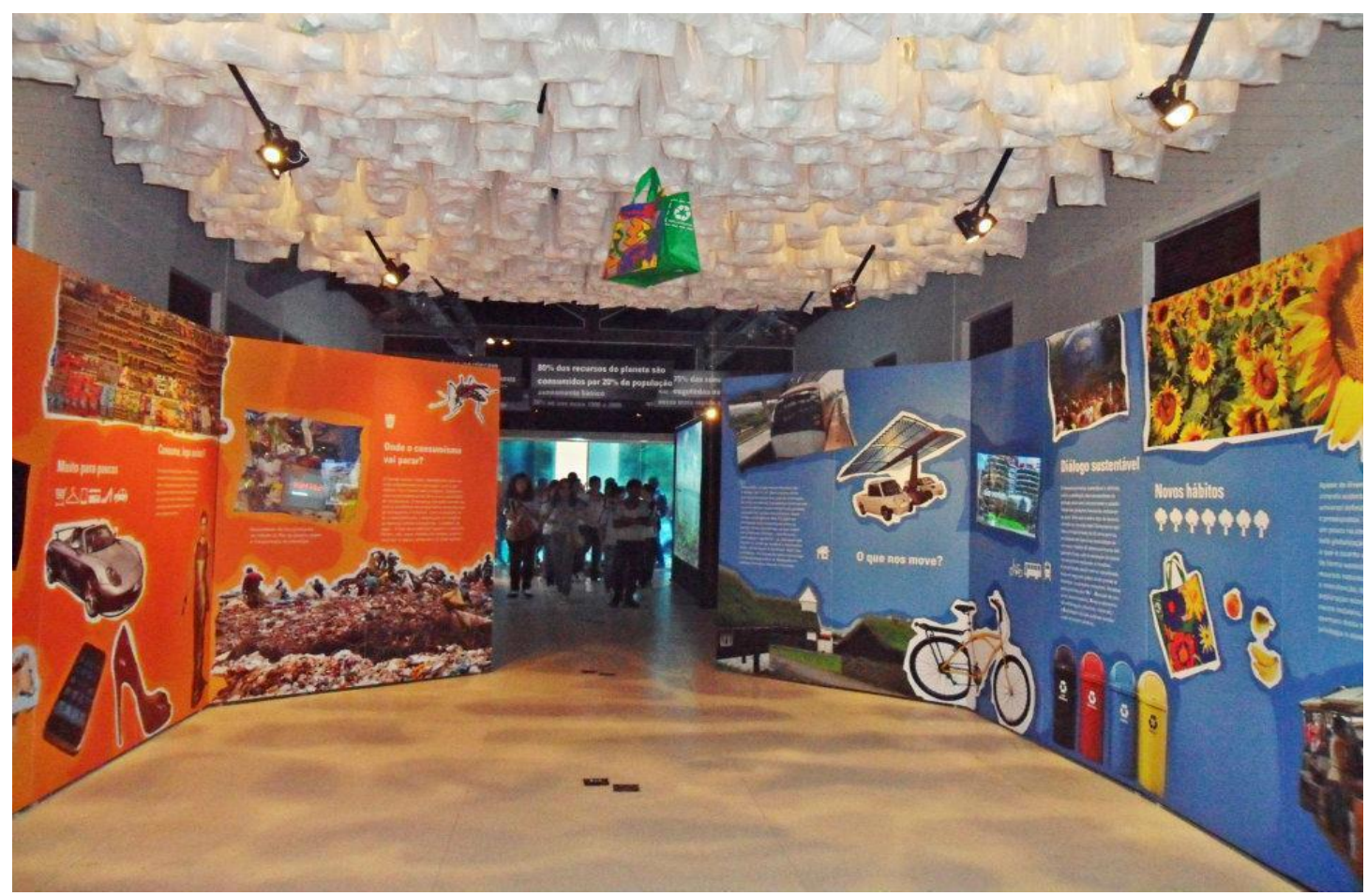

Fonte: Arquivo pessoal

Nesta etapa os mediadores refletiam conjuntamente com os vistantes sobre como nossos hábitos e modo de vida vem atingindo o meio ambiente e traçavam uma relação entre luxo, fome, consumo, lixo, modo de produção e descarte do lixo (Lomy; 2005). Os debates eram conduzidos de forma a relacionar modo de produção, o consumismo que o sustenta, degradação do planeta, saúde e risco de colapso da nossa sociedade, além de saúde e lixão.

Após as discussões, os visitantes eram questionados se haveria ou não uma forma de mudar os "cenários" negativos, e a partir de suas respostas ou ausência delas, direcionados aos "cenários" positivos, onde se destacam novas matrizes energéticas, novas soluções arquitetônicas e de engenharia, soluções locais integradas a uma rede ampliada global, combinações de soluções, concepções coletivas (Ex: destinação do lixo, durabilidade dos produtos, cidadania ativa e participativa, exigência de atendimento as necessidades ambientais e sociais), defesa de um modo de produzir que considere o impacto no meio 
ambiente e saúde de quem trabalha e consome e mudanças de atitudes individuais.

Neste módulo pudemos observar grande interesse e envolvimento, principalmente do público adolescente e adulto. Esta parte da mediação durava em média 40 minutos $^{2}$, sendo muitas vezes o tempo ultrapassado. Por meio de nossa observação empírica este foi o módulo mais explorado pelos visitantes

A abordagem do segundo módulo foi diferente entre o público até 11 anos e a partir de 12 anos, se moldando de acordo com a maturidade dos grupos recebidos, sendo muitas vezes utilizado o roteiro para o público acima de 12 anos com o público a partir de 10 anos.

Com o público de até 12 anos foi contada a história "O Saci e a reciclagem do lixo", de autoria de Samuel M. Branco, em frente ao Lixômetro ${ }^{3}$ e os cenários negativos. Após a história o público realizava diversas perguntas sobre o tema abordado, sendo levado a identificar tanto no cenário negativo quanto no positivo pontos em comum com a história. Perguntas chaves também eram feitas pelas mediadoras a fim de levá-los a refletir e identificar principalmente os caminhos do lixo (de onde vem e para onde vai), seu impacto em nossa vida (doenças que pode causar), nossa responsabilidade sobre o lixo e alternativas de mudanças em relação a degradação do meio ambiente. Neste ponto destacamos principalmente a relação consumo, lixo produzido e saúde. Todos os pontos foram abordados levando em conta o "pensar no coletivo e agir coletivamente".

O último módulo, "interativo", apresentou ao público equipamentos onde o grupo, após ser dividido, exploravam de forma dinâmica questões sobre energia, produção de alimentos, uso da água, reciclagem, trabalho comunitário e cooperativo, através dos aparatos "Mercado", "Casa de Furnas", "Linha do Tempo", "Bicicleta", "Sensor de Movimentos" e "Pets".

\footnotetext{
2 Duração total da visita 1 hora e meia.

${ }^{3}$ Computador que se encontrava dentro do cenário negativo, próximo a imagem do lixão, onde era contabilizada a tonelada de lixo produzida diariamente na cidade do Rio de Janeiro desde a inauguração da exposição.
} 
O "Mercado" tem por objetivo mostrar ao visitante o valor ambiental de alguns dos produtos de nosso uso diário (Loureiro; 2012). Ao passar o leitor no código de barras dos produtos expostos, o visitante obtém informações sobre a quantidade de água utilizada na fabricação do mesmo ou o tempo em que o material exposto leva para se decompor no meio ambiente. Em alguns casos são apresentadas alternativas para reciclagem de determinados produtos. Questões relativas ao atual sistema produtivo de alimentos (agropecuária e agronegócio), foram abordadas pelos mediadores, apresentando alternativas como agricultura familiar e outras formas históricas de produção coletiva de alimentos.

A "Casa de Furnas" mostra ao visitante o consumo real de energia (Kw/h) dos eletrodomésticos, eletroeletrônicos e lâmpadas através da maquete de uma casa (UNESCO). Ao apertar o botão correspondente a um aparelho, a casa mostra o valor do consumo máximo ou mínimo deste. Quando todos os aparelhos são ligados, há uma sobrecarga no sistema e a casa apaga, explicando o motivo do ocorrido. A casa também dá aos visitantes dicas para economizar energia elétrica. Neste aparato foram trabalhadas, com o público, soluções individuais e formas de pressão ao governo, além de levantar questões sobre as lâmpadas e suas alternativas, soluções arquitetônicas (Ex: substituir a água potável das descargas) e destinação do lixo doméstico.

$\mathrm{Na}$ "Bicicleta", ao pedalar, um dínamo transforma a energia cinética produzida pelo visitante em energia elétrica, ascendendo um painel ligado à mesma. À partir do esforço feito na bicicleta para acender o painel foi trabalhado junto aos visitantes trabalhar a ideia de coletividade (sozinho o esforço é inútil, precisamos da ajuda de todos para mudarmos a situação do planeta).

O sensor detecta a mão do visitante e através do movimento realizado por este, muda a paisagem de uma cidade projetada em telão. No espaço onde o movimento do visitante é detectado, a paisagem muda de degradada para sustentável. Pudemos dialogar com os visitantes sobre iniciativas comunitárias de mudanças de hábitos como a separação do lixo e do óleo, assim como a implantação de coleta seletiva, entre outros, dando ênfase na participação da 
comunidade para que haja mudanças locais. Foram discutidas como a degradação ambiental pode atingir a nossa saúde e da nossa comunidade (ex: poluição dos rios, solo, ar, falta de serviços básicos como saneamento etc...), fazendo o visitante refletir sobre o próprio bairro, a fim de identificar problemas possíveis de serem resolvidos.

A "Linha do Tempo" apresentou aos visitantes os eventos relacionados à degradação do meio ambiente ocorridos desde 1962, ano escolhido como marco inicial por conta da publicação do livro "Primavera silenciosa", à 2012 com a realização da "Rio + 20". O principal objetivo é levar o visitante a conhecer os principais eventos e acontecimentos ocorridos até 0 momento relacionados à degradação do meio ambiente. Concomitante ao processo em surge na sociedade civil em vários pontos do planeta a percepção da importância da luta contra a degradação ambiental e a inclusão na pauta das nações unidas deste tema com a realização das conferências internacionais (RADIS) ${ }^{4}$. O funcionamento do interativo era bem simples: o visitante, ao aproximar a mão nas extremidades da tela, a mesma voltava ou avançava a linha do tempo. Então os visitantes estimulados pelo mediador discutiam os eventos em grupo.

A atividade da parede de garrafas pets, que tem como proposta fazer com que os visitantes expressassem seus desejos para um futuro sustentável, foi realizada com quase todos ${ }^{5}$ os visitantes da exposição, de todas as idades. As crianças ainda não alfabetizadas foram orientadas a desenhar seus desejos, para que estas por não saberem escrever, não fossem excluídas da atividade. Os bilhetes depositados nas garrafas ainda estão em fase de transcrição e posteriormente serão feitas análises ${ }^{6}$.

\section{Proposta educativa para mediação da exposição Nós do Mundo}

\footnotetext{
${ }^{4}$ Revista RADIS comunicação e saúde.

${ }^{5}$ Exceto os que não desejaram realizar a atividade.

${ }^{6}$ Serão realizadas a partir das análises do material produzidos pelos visitantes, uma pesquisa avaliativa da exposição.
} 
Com o objetivo de levar o público à reflexão e debate dos problemas ambientais e sociais apresentados em nossa introdução, tomando como ponto de partida a nossa relação com o ambiente em que vivemos, a exposição Nós do Mundo trouxe uma proposta educativa organizada de forma a facilitar sua compreensão por diversos públicos.

Trataremos aqui sobre a formação dos mediadores; os objetivos da mediação da exposição; e os roteiros de mediação desenvolvidos pelos próprios mediadores em conjunto com o educador, responsável pela organização da formação dos bolsistas, membro do Serviço de Educação de Ciência da Saúde do Museu da Vida (SEDUCS-MV).

A proposta educativa para a mediação da exposição "Nós do Mundo" foi elaborada e implementada antes e durante o período no qual a exposição ficou disponível no salão de exposições temporárias do Museu da Vida, entre maio e julho de 2012. Sendo revista e reestruturada a medida que obtivemos o retorno do público visitante sobre a mesma. Contudo, a primeira versão dos roteiros e os objetivos da formação dos mediadores e das atividades foram previamente debatidos em reuniões no serviço de educação do museu com a curadora.

Buscamos orientar nossa proposta em consonância com o pressuposto teórico da urgência em debatermos com a sociedade o nível critico de degradação ambiental atual de nosso planeta.

A aceleração do desenvolvimento tecnológico e econômico levou o sistema a demandar um consumo vertiginoso de recursos materiais. Esse consumo constitui uma das expressões materiais do acirramento das contradições estruturais do capitalismo.

A contradição entre forma social, baseada na exploração do trabalho humano nos marcos de um sistema produtivo assentado na ciência como força produtiva principal, expressam-se através de uma corrosão acelerada dos fundamentos ecológicos do planeta (Lomy; 2005). 
Dessa forma, o colapso ecológico generalizado torna-se uma possibilidade que surge no horizonte. Mas o problema não se limita à um eventual fim possível da vida humana, pois não menos cruel pode ser o "sobreviver" de uma sociedade e de uma natureza totalmente degradadas, como nos vislumbram alguns livros e filmes sombrios e terrivelmente racionais de ficção cientifica.

Portanto, o trabalho da proposta educativa contribui para pautarmos também a formação dos mediadores da exposição. Estimulando-os a assumirem uma perspectiva crítica diante dos problemas ambientais da atualidade e sua relação com o capitalismo. Sensibilizando-os para a importância do debate sobre as soluções coletivas e colaborativas no enfrentamento dos problemas da nossa sociedade em particular os ambientais (Loureiro; 2012).

A proposta educativa objetivou fornecer subsídios para que os mediadores, explorando os recursos da exposição, provocassem no público reflexão sobre a problemática sócio-ambiental local e global tratando os seguintes conceitos: mudanças climáticas, sustentabilidade, consumo consciente, justiça ambiental, conflitos ambientais, educação ambiental, a relação modo-de-produção e meioambiente, as relações entre Estado e sociedade civil, a relação entre degradação ambiental e saúde.

As provocações, bem como as atividades, e debates suscitados pela mediação da exposição, buscou constituir reflexões e vivências que instigassem a curiosidade dos visitantes sobre a crise ambiental da atualidade, que se agrava na medida em que avança as contradições do sistema dentro de uma dinâmica que amplia a predominância de interesses privados em detrimento de interesses públicos, enfraquecendo a perspectiva de uma cidadania com plena participação social (Loureiro; 2012).

A mediação também buscou de maneira equilibrada apresentar não só as possíveis soluções teóricas para o enfrentamento do problema da crise ambiental, como também soluções concretas e bem sucedidas desse enfrentamento, por meio da exposição dialógica (Freire; 1996) dos mediadores, buscando evitar uma visão nilista e passiva diante do quadro de crise conjuntural que enfrentamos, 
construindo com este método novas questões e possíveis novos caminhos a partir da fala dos próprios visitantes.

\section{A formação dos mediadores}

A equipe de mediação foi constituída da mediadora, graduada em história, que permaneceu em horário integral, também exercendo função de supervisora dos demais mediadores; e mais quatro mediadores de nível médio, em período parcial, sendo três oriundos do antigo curso de formação de monitores do Museu da Vida, e uma do atual Programa de Jovens Aprendizes de Produção Cultural em Divulgação Científica ${ }^{7}$.

A formação dos mediadores se dividiu em dois momentos: um primeiro chamado de formação inicial, composto por cinco encontros, um em cada dia da semana com duração de quatro horas diárias onde foram realizadas pesquisas em sites especializados na Internet, debates sobre textos após leituras dos mesmos e feitura de resumos (estes feitos em casa). Os debates eram conduzidos pelo educador do SEDUCS-MV, responsável pela formação dos mediadores em conjunto com a mediadora / supervisora.

Também ocorreu exibição e debate do documentário "Chico Mendes - Eu quero viver" de autoria Adrian Cowell (1999), produção independente; uma conversa sobre a elaboração conceitual com a curadora da exposição Vanessa $F$. Guimarães e com a desing Aparecida Ramos, envolvida na produção da exposição. Por fim, participaram da confecção de acabamentos para a mesma compreendendo pelo menos parcialmente a complexidade e nível de envolvimento necessário para a produção de uma exposição como esta.

O segundo momento visou à formação continuada, realizada por meio de um treinamento para utilização dos aparatos interativos durante os dois primeiros

7 Tanto o antigo curso de monitores como o atual programa jovens aprendizes desenvolvidos pelo Museu da Vida tem como público alvo jovens estudantes de escolas públicas de nível médio ou moradores do entorno da FIOCRUZ (principalmente os bairros de Manguinhos e da Maré). 
dias de funcionamento da exposição, cabendo ao educador do serviço de educação do museu a responsabilidade pelo treinamento, selecionando pequenos textos e reportagens sobre temas da exposição para que os mediadores pudessem elaborar breves resumos.

Também foram realizadas reuniões alternadas no começo e no final da semana, onde foram construídas novas versões, voltadas para públicos de faixa etária distinta do roteiro inicial de visitação da exposição, assim como debate dos conceitos da mediação e a interação com o público, articulando teoria e prática na formação dos mediadores.

A seleção da supervisora considerou sua experiência e envolvimento em outras exposições anteriores no Museu da Vida, tendo um processo de formação à parte, onde teve contato com o texto "base" da exposição, desenvolvido pela curadora, e demais textos de maior densidade selecionados pela equipe SEDUCS - MV, além de participar de reuniões de planejamento da proposta educativa e sobre os conceitos à serem trabalhados na mediação da exposição como já citado. Por fim, participou do planejamento e da formação dos demais mediadores, da elaboração e implementação dos roteiros da exposição.

Durante todo o período da exposição o educador responsável SEDUCS MV acompanhou a equipe de mediação da exposição por meio de reuniões de formação e relatórios semanais das atividades confeccionados pela mediadora supervisora, também encaminhados a coordenação do serviço de visitação e atendimento ao público $\operatorname{SVAP}^{8}$ e a curadora da exposição.

\section{Objetivos da mediação}

O principal objetivo da mediação no espaço expositivo foi provocar reflexão nos visitantes sobre o impacto da opção social pelo nosso modo e vida na degradação ambiental do nosso planeta, na saúde e os conseqüentes riscos para

\footnotetext{
${ }^{8}$ Serviço de Visitação e Atendimento ao Público do Museu da Vida.
} 
nossa espécie. Apontando possíveis soluções, de caráter coletivo, para problemas ambientais por meio da utilização dos recursos da exposição Nós do Mundo.

Para o alcance do objetivo geral, traçamos como específicos a identificação de problemas de degradação ambiental na nossa sociedade que afetam nossa saúde, o estímulos à curiosidade sobre a origem dos problemas de degradação ambiental. Visamos ainda sensibilizar o visitante para os riscos à biodiversidade do nosso planeta causados pelo nosso modo de produção, provocar a reflexão sobre a relação entre consumo e miséria, bem como a relação concentração de renda e pauperismo com o modo de produção vigente em nossa sociedade.

E no escopo dos nossos objetivos específicos, identificamos a relação entre o consumismo desenfreado e a produção de lixo em nossa sociedade, apresentamos os efeitos no meio ambiente das principais matrizes energéticas usadas em nossa sociedade, estimulamos à curiosidade pelo uso alternativo e complementar das fontes de energia consideradas limpas, provocamos a reflexão sobre a relação dialética entre as contribuições individuais e coletivas para solucionar os problemas que afetam o meio ambiente, promovemos o debate sobre desenvolvimento de metodologia de organização social colaborativa, utilizando o jogo "Unidos para produzir um planeta terra saudável" e estímulamos à reflexão sobre formas alternativas de produção (agrícola e industrial) que evitem o desperdício de água, assim como o mau uso dos demais recursos naturais e prejuízo a saúde dos seres humanos.

\section{Jogo "Unidos para produzir um planeta terra saudável"}

Foram realizadas duas atividades distintas para melhor trabalharmos com o público infantil e adolescente. Para o primeiro a atividade realizada foi a contação da história "O Saci e a reciclagem do lixo" e com os adolescentes o jogo "Unidos para produzir um planeta terra saudável". 
Daremos destaque aqui ao jogo, onde obtivemos grandes reflexões por parte do público sobre questões relacionadas a saúde, meio ambiente, consume e desigualdade social.

O jogo em questão faz parte da pesquisa de doutorado de Maria Mercês N. Vasconcellos e foi elaborado a partir da colaboração entre museu e escolas da região de Manguinhos, priorizando o interesse de atendimentos públicos.

"Trata-se de um trabalho não alienado, que visa contribuir para a cultura modificadora das condições objetivas da realidade social. Modificações decorrentes das atuações de agentes sociais individuais, coletivos ou inseridos em tal realidade. Espera-se que esta cultura possa subsidiar o processo de construção de uma sociedade mais equânime, democrática, justa, solidária, prudente, prospectiva e responsável, do ponto de vista socioambiental" (Vasconcellos, 2008).

O jogo "Unidos para produzir um planeta terra saudável" é de caráter cooperativo, e tem como objetivo transformar a realidade negativa em positiva, a partir de resoluções coletivas dos problemas apresentados pelas cartas promovendo a construção colaborativa (Freire, 1996) em oposição a cultura individualista e meritocrática de nossa sociedade. Tal objetivo deve ser realizado dentro de um tempo limite, sendo o "tempo", o único adversário do grupo.

As cartas do jogo foram desenvolvidas à partir de cartas escritas por estudantes da Rede Pública Municipal de Ensino do Rio de Janeiro, no Projeto Tecendo Redes por um Planeta Terra Saudável ${ }^{9}$, em Manguinhos. Estas estão divididas por temas e cores, sendo azuis, laranjas, verdes, vermelhas, brancas e amarelas.

Nas cartas "vermelhas" o texto é composto por frases dos estudantes sobre como é hoje a vida em Manguinhos e como eles imaginam que será no futuro e o

\footnotetext{
9 Ação colaborativa de Educação Ambiental construída entre instituições científicas (Jardim Botânico - RJ, Museu de Astronomia e Ciências Afins, Museu da Vida - FIOCRUZ) e escolas municipais de seus em tornos, promovendo a popularização da ciência.
} 
objetivo é levar os jogadores a refletirem sobre a realidade local da região e como podemos contribuir para a produção social da saúde.

As cartas "Laranjas" apresentam informações sobre museus, em especial o Museu da Vida, e tem por objetivo a ampliação cultural dos jogadores e estímulo para a produção social da saúde. As cartas "Verdes" apresentam informações a fim de provocar uma reflexão de temas para que haja atuação dos cidadãos neste processo produção.

As "Brancas" apresentam textos que levam a refelxão por parte dos jogadores sobre História e Saúde no território em que se localiza sua escola e sobre o papel desta nas possíveis soluções de problemas socioambientais.

E as cartas "Azuis", à partir de disciplinas escolares (Educação Física, Artes, Língua estrangeira, Matemática, ciências, História, Geografia e Língua Portuguesa) trata do problema de falta de água potável e a poluição desta.

É importante ressaltar que durante a dinâmica do jogo, os temas foram adaptados considerando a região e realidade socioambiental de cada escola, buscando sempre levar os jogadores a uma reflexão ampla que, embora parte de seu ambiente, pudesse ser ampliada a outras realidades sociais, tendo como entendimento de desigualdade social características sociais que colocam em desvantagem de um grupo em relação a outro (Barata, 2009).

Imagem 2 


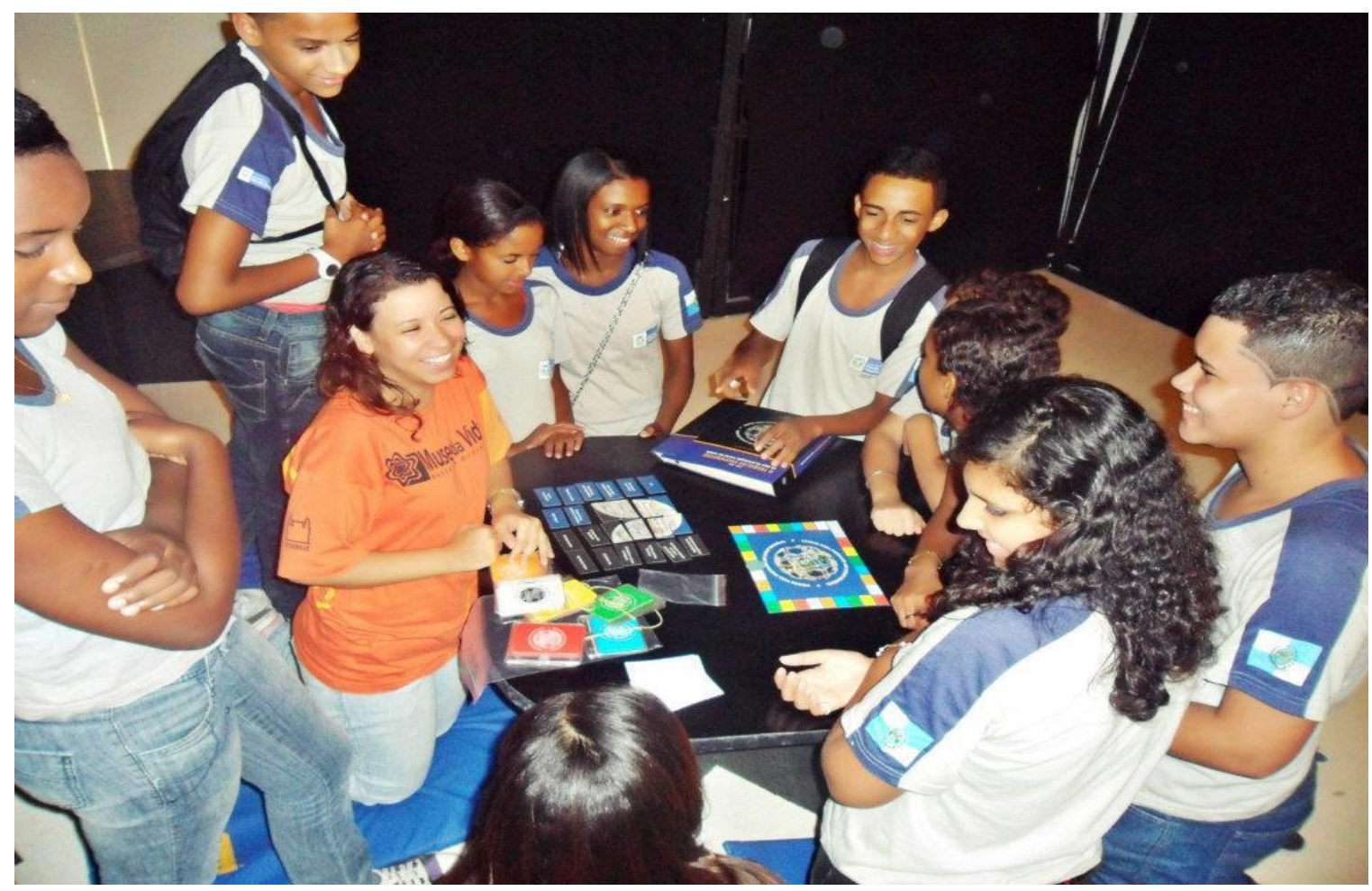

Fonte: Arquivo pessoal

O jogo foi utilizado amplamente e diversas vezes com grupos de estudantes, tanto da rede pública quanto particular, assim como com grupos familiares que demonstraram interesse em jogá-lo ou mesmo só conhecer sua dinâmica e produção. A atividade do jogo foi realizada com o público a partir de 12 anos, em grupos de até 08 jogadores ${ }^{10} \mathrm{e}$ uma mediadora, sendo todas as participações voluntárias. Os estudantes eram convidados a participarem de um jogo "diferente" do que eles estavam, em sua maioria, acostumados a jogar, um jogo "cooperativo". Muitos, à princípio recusavam, mas logo se mostravam interessados a participar.

Durante a mediação do jogo diversas discussões foram levantadas, principalmente no que diz respeito a desigualdade social. Percebemos por parte de muitos adolescentes a recusa de participar de um jogo de caráter cooperativo, por acreditarem ser chato ou "sem sentido"11, no entanto a maior parte destes

\footnotetext{
${ }^{10}$ No entanto os observadores podiam livremente participar dos debates propostos.

${ }^{11}$ Por não haver um único ganhador, como nos jogos competitivos.
} 
demonstraram mudança de opinião após presenciarem ou participarem do jogo.

Um dos pontos que entendemos como mais importante é que, embora o jogo tenha sido elaborado a partir de entrevistas com jovens de escolas públicas, pudemos identificar questionamentos comuns a crianças da rede particular e de bairros com melhores infra-estruturas. Também identificamos reações de jovens alheios à realidades sociais diferentes da própria.

Os relatos dos jogadores após o termino do jogo, assim como as observações feitas a partir da mediação deste, demonstram o quando enriquecedor foi o jogo para todos que dele participaram de alguma forma. A troca de experiências e saberes que o jogo proporcionou veio a facilitar a reflexão sobre os conteúdos da exposição e acrescentar novas informações a esta.

\section{Considerações Finais}

Pensar a sociedade tendo como parâmetro o ser humano exige a superação da lógica do capital, que tem no individualismo, no lucro e na competição seus fundamentos. Romper com a separação, em nossa sociedade, entre os homens que pensam e os que trabalham é resgatar o sentido estruturante da vida, da educação sua relação com o trabalho, a cultura e o meio ambiente (Mészaros, 2005). Liberando as possibilidades criativas e emancipatórias dos homens.

Logo se desejamos promover um debate ambiental que mude atitudes e comportamentos, e não apenas estes últimos, devemos compreender como são os ambientes de vida, qual a posição ocupada pelos diferentes grupos e classes, como estes produzem, organizam-se e geram cultura, bem como as implicações ambientais disso, para que uma mudança possa ser objetivada (Loureiro, 2012).

Ao se destacar a práxis educativa, crítica e dialógica, é preciso apontar e contribuir na promoção junto à sociedade dos processos participativos que favoreçam a superação das relações de poder consolidadas e garantir o exercício 
da cidadania, principalmente dos que se encontram em situação de maior vulnerabilidade social.

A exposição "Nós do Mundo", tendo os fundamentos acima como pilares do seu trabalho e diálogo com a sociedade apontou a emergência de inumeras questões e possibilidades que não podem ser plenamente exploradas neste espaço. Porém, não poderíamos terminar este relato sem indicarmos alguns pontos que nos parecem fundamentais para ressaltarmos a importância de garantirmos um maior espaço para essa temática e seu debate crítico e emancipador em nossos museus e espaços de educação não formal.

O primeiro ponto inconteste em todo esse processo é que há uma demanda da sociedade por se debater os problemas ambientais e as desigualdades sociais, mesmo que na maioria das vezes os visitantes não percebam as imbricações das questões, foi nosso dever evidenciar a indissociabilidade desta relação.

O trabalho com a percepção que somos todos sujeitos históricos proporcionou ótimos embates com certo nível de niilismo e "descrença" que por vezes aparecia na fala de alguns visitantes, sendo o método dialógico da mediação fundamental para uma troca intensa entre os próprios visitantes, na totalidade das vezes em que tal discurso surgiu, desmontando a argumentação fatalista apontando para uma reflexão mais aprofundada sobre as determinações das questões abordadas.

A problematização na exposição de sermos sujeitos históricos passava por outra questão importante a da participação popular, termo que muitos visitantes já tinham escutado, mas que a maioria não conseguia discernir claramente do que se tratava, como se estruturava e para onde poderia conduzir a nossa sociedade. Esse debate bravamente enfrentado pela exposição e seu trabalho de mediação também valeria uma reflexão a parte. Sabendo que este é um debate determinante na construção de processos em que os grupos expropriados podem adiquirir centralidade na sociedade, enfrentando suas contradições e explicitando conflitos da mesma. 
A disposição em discutir e implentar nas atividades lúdicas a perspectivas de valores que normalmente são negligenciados em nossa sociedade como o de colaboração em oposição ao de competição (base do individualismo) e a explicitação de um nova possibilidade de se organizar coletivamente frente a desafios bem concretos do nosso cotidiano, demonstrou ser uma poderosa possibilidade de reflexão cultural. Este é outro viés de debate que também precisaria de maior profundidade.

Os pontos anteriores foram observados pela equipe de mediação envolvida, pela curadoria, e pelo Serviço de Educação do museu, por meio de suas reuniões, apontamentos e relatórios. Há ainda aguardando tratamento dois sacos de aproximadamente três quilos de mensagens de visitantes recolhidas ao longo do período da exposição. As mensagens foram depositadas dentro das garrafas pets que compunham o "módulo interativo", sempre ao final da visita, este material com certeza descortinará ainda maiores possibilidades de reflexão a respeito de tudo aqui já exposto e provavelmente de outras questões que nos escaparam.

Finalizamos destacando que espaços de cultura como bibliotecas, centros culturais e museus, não somente as escolas (que devem também promover tais reflexões), são agentes fundamentais na colaboração e na construção de um debate cultural visando a transformação societária que favoreça o direito democrático de atuação local e global das pessoas de forma organizada e crítica.

\section{Referência}

BARATA, Rita Barradas. Como e por que as desigualdades sociais fazem mal a saúde. Rio de Janeiro: Editora Fiocruz, 2009.

BENJAMIN, Walter. Rua de Mão Única. São Paulo: Brasiliense, 1987.

FREIRE, Paulo. Pedagogia da Autonomia: saberes necessários à prática educativa. 12ª ed. São Paulo: Paz e Terra, 1999.

IANNI, Octávio. Teorias da Globalização. Rio de Janeiro: Civilização Brasileira, 1995. 
LOBO, Roberta (Org.). Crítica da Imagem e Educação: reflexões sobre a contemporaneidade. Rio de Janeiro: EPSJV/Ed. FIOCRUZ, 2010.

LOMY, Michel. Ecologia e Socialismo. São Paulo: Cortez, 2005.

LOUREIRO, Carlos F. B. Sustentabilidade e Educação: um olhar da ecologia política. São Paulo: Cortez, 2012.

MARENGO, José A. VALVERDE, Maria C. Caracterização do clima no século XX e cenários de mudança de clima para o Brasil no século XXI usando os modelos do IPCC-AR4. In: Revista Multiciência: mudanças climáticas. Campinas. №. 8; 2007.

MÉSZAROS, István. Produção destrutiva e estado capitalista. São Paulo: Ensaio, 1989.

. Educação para além do capital. São Paulo: Boitempo,

2005.

VASCONCELLOS, Maria das Mercês Navarro. Educação ambiental na colaboração entre museus e escolas: limites, tensionamentos e possibilidades para a realização de um projeto político pedagógico emancipatório. Rio de Janeiro: UFF; 2008. 